\title{
Costing of Haemodialysis and Continuous Ambulatory Peritoneal Dialysis procedures performed at National Institute of Nephrology, Dialysis \& Transplantation, Sri Lanka
}

\author{
Malalasekara LI, De Silva Dileep.
}

\begin{abstract}
Introduction: Chronic Kidney Disease(CKD) is a rising epidemic. It is estimated that annually 1000 patients of End Stage Renal Failure are newly diagnosed. They require dialysis therapy, until kidney transplantation.
\end{abstract}

Haemodialysis(HD) is the widely practiced dialysis method used today. The Continuous Ambulatory Peritoneal Dialysis(CAPD) is the other dialysis option. There are studies done on costing of HD, no such studies are available for CAPD in Sri Lanka.

Objective: To compare the provider cost of HD and CAPD. performed at National Institute of Nephrology, Dialysis and Transplantation (NINDT) during the month of February 2016.

Methodology: Adescriptive cross sectional retrospective study, conducted among patients who underwent HD and CAPD for one month. Step down approach was used to calculate the costs.

Results: Study reveals that the cost for a patient who undergoes HD for one month is Rs. 102,420. Cost for CAPD procedure for a patient during the 1 st month was Rs 87,485 including the five day training. From the second month home based CAPD cost per month is Rs. 77,520 .

Most Asian countries adopt 'CAPD first policy' for Renal Replacement Therapy (RRT). With the increasing number of ESRF patients in Sri Lanka a need of rationalizing RRT exists.

According to the study the annual cost for a HD patient is Rs $1,229,040$ and the same for CAPD patient is Rs 940,205 .

Conclusion: CAPD is $25 \%$ less costly than HD.

Recommendation: Increase the facilities available for CAPD at more hospitals.

Key Words: Haemodialysis, Continuous Ambulatory Peritoneal Dialysis, Provider Cost

\section{Introduction}

Chronic Kidney Disease (CKD) is rising and becoming an epidemic in Sri Lanka. Diabetes Mellitus, Hypertension, Snake bites, use of pesticides are among the causes that can lead to End Stage Renal Failure (ESRF).

People diagnosed with CKD can be categorized in to five stages, by referring to Glomerular Filtration Rate values (GFR) as given below.

\section{Table 1 CKD Stage based on Glomerular Filtration Rates}

\begin{tabular}{|c|c|c|}
\hline $\begin{array}{l}\text { CKD } \\
\text { Stage }\end{array}$ & Kidney Function & $\underset{(\mathrm{mL} / \mathrm{min} / 1.73 \mathrm{~m} 2)}{\text { value }}$ \\
\hline One & $\begin{array}{l}\text { Kidney damage } \\
\text { with normal kidney } \\
\text { function }\end{array}$ & 90 or above \\
\hline Two & $\begin{array}{l}\text { Mild loss of kidney } \\
\text { function }\end{array}$ & $60-89$ \\
\hline Three & Mild to moderate loss & $30-59$ \\
\hline Four & Severe loss & $15-29$ \\
\hline Five & Kidney failure & $\begin{array}{l}\text { Less than } 15 \\
\text { (Dialysis) }\end{array}$ \\
\hline
\end{tabular}

Source: National Kidney Foundation

http://www.kidney.org/atoz/content.

\section{Justification}

The purpose of this study is to summarize the evidence surrounding CKD patients wellbeing according to dialysis modality HD and CAPD to estimate and compare the provider cost involvement for the choice.

The HD which is commonly used in Sri Lanka has limitations due to requirement of equipment and trained manpower.

The other dialysis method CAPD is used successfully in many countries. Both methods of dialysis have advantages and disadvantages. The main advantage of haemodialysis is that it is being carried out by trained health professionals who can identify unexpected outcomes. The patient will also experience the emotional support from other patients undergoing haemodialysis. The main disadvantages of haemodialysis are, it can cause circulatory problems and changes in blood pressure. 
The main advantages of CAPD are, the patient will have more freedom as it is home based and does not need needles for the process. The disadvantages of CAPD include, the difficulty for some patients to conduct the procedure and it may increase the risk of peritonitis.

\section{Problem Statement}

Sri Lanka is faced with a fast spreading epidemic of kidney diseases. Nearly 1000 patients reach ESRF annually and require regular dialysis.

Facilities available for haemodialysis are limited. State sector is unable to fulfill the HD needs of the patients. Therefore, other available optimal methods of dialysis need to be considered. CAPD is one such method. It is appropriate to estimate and compare the costs involved for these two methods.

\section{General Objective}

To compare the provider cost of HD and CAPD performed at NINDT during the month of February 2016.

\section{Specific Objectives}

1. To estimate the provider cost of
a. Haemodialysis
b. Continuous Ambulatory Peritoneal Dialysis

2. To compare provider costs of haemodialysis and continuous ambulatory peritoneal dialysis.

\section{Literature Review}

\section{Chronic Kidney Disease(CKD) and End Stage Renal Failure (ESRF)}

Despite having new treatment methods to stop or slow down the progression of Chronic Kidney Disease, it has now become a worldwide health crisis (Levey et al., 2007).

The incidence of ESRF in Sir Lanka is rising with the figure of 232 persons per million population. The most common reasons for rising incidence of CKD are Diabetes and Hypertension (Jha, 2009). In North Central parts of the country, CKD due to unknown etiology (CKD-u) too is being reported. It has mostly affected the farmers of age between 30 to 60 years. They belong to the most productive working years. Unfortunately, since the symptoms appear late or not diagnosed at the beginning, patients end up with the need of renal replacement therapy or kidney transplant. By the end of year 2023 it is estimated that the number of CKD-u patients will be over 25000 (Alwis, 2013). Morbidity in this young group has affected the production.

\section{Methodology}

This study on CKD was planned to determine the costs involved for various dialysis methods and compare them. In this study both heamodialysis and CAPD units of the institute were taken as direct cost centers and unit cost is calculated separately for the two therapies.

\section{Study design}

Descriptive cross sectional study design is used. The main components included provider cost estimation of both methods and cost comparison between them.

\section{Study setting \& Study population}

All patients who underwent HD and CAPD at NINDT.

\section{Study period}

The study was conducted from 1stof February 2016 to 29th February 2016

\section{Study Instrument}

Check list was developed.

\section{Data collection:}

The required data was collected by examining relevant documents and interviews with appropriate officers.

\section{Identification of cost centres}

Three cost centers identified were: overhead (Administrative office, water, electricity, etc..), intermediate (laundry, surgical stores, etc..) and final (Haemodialysis and CAPD units).

\section{Data Analysis and Results}

Table 2 below summarizes the cost incurred when providing $\mathrm{HD}$ and CAPD services for the patients undergoing dialysis for the study month.

Table 2: Cost calculations for HD Unit and CAPD Unit for a month

\begin{tabular}{lrr}
\hline & $\begin{array}{r}\text { HD Unit } \\
\text { Rs. }\end{array}$ & $\begin{array}{r}\text { CAPD Unit } \\
\text { Rs. }\end{array}$ \\
\hline $\begin{array}{l}\text { Total recurrent cost } \\
\text { per month }\end{array}$ & $5,431,854$ & $1,311,515$ \\
$\begin{array}{l}\text { Total Capital consumption } \\
\text { cost per month }\end{array}$ & $1,007,144$ & 15,891 \\
\hline Total cost per month & $\mathbf{6 , 4 3 8 , 9 9 8}$ & $\mathbf{1 , 3 2 7 , 4 0 6}$ \\
\hline
\end{tabular}

Total monthly cost for HD unit is Rs. 6,438,998 which includes recurrent cost of Rs. 5,431,854 and the capital consumption cost of Rs. 1,007,144. The total cost per month for CAPD unit is Rs. 1.327,406 which includes Rs. 1,311,515 as recurrent cost and Rs. 15,891 as capital consumption cost. 
A special feature that can be noticed here is that capital consumption cost of CAPD is only Rs. 15,891 and same for $\mathrm{HD}$ is as high as Rs.1,007,144.

Total monthly cost for haemodialysis unit

Number of haemodialysis sessions per month

Cost per each hemodialysis session

Total cost for one patient who is undergoing every

other day dialysis per month Rs. 6,828 X 15

(Average cost per month per patient for HD)

Total monthly cost for CAPD unit

Total cost of CAPD for the first month inclusive of

five day training per patient

Total cost for home based CAPD per month per person including the surgical consumables provided by the NINDT from the second month Rs. 2584 x 30 days

Total cost for CAPD for one year

Rs. $87,485+852,720$ (77,520 x 11 months $)$

Average cost per month per patient for CAPD

Rs. 940,205/12

$\begin{array}{rr}= & \text { Rs. } 6,438,998 \\ = & 943 \\ = & \text { Rs. } 6,828 \\ = & \text { Rs. } 102,420 \\ = & \text { Rs. } 1,327,406 \\ = & \text { Rs. } 87,485 \\ & \\ = & \text { Rs. } 77,520 \\ = & \text { Rs. } 940,205 \\ = & \text { Rs. } 78,350\end{array}$

Table 3 below summarizes the provider cost for CAPD and HD processes.

Table 3: Comparison of average monthly and annual treatment cost between CAPD and $\mathrm{HD}$

\begin{tabular}{|c|c|c|c|}
\hline Period of $\mathbf{T x}$ & & $\begin{array}{r}\text { Total cost for a } \\
\text { patient for } \\
\text { daily CAPD } \\
\text { Rs. }\end{array}$ & $\begin{array}{r}\text { Total cost for a } \\
\text { patient for every } \\
\text { other day HD } \\
\text { Rs. }\end{array}$ \\
\hline First month & $\begin{array}{l}\text { CAPD: Training cost for } 1 \text { st } \\
\text { five days Rs. } 22,885 \\
\text { (Rs. } 4,577 \text { x } 5 \text { days) } \\
\text { CAPD :Cost for continuation at } \\
\text { home with provided chemicals } \\
\text { Rs. } 64,600 \\
\text { (Rs. } 2,584 \text { x } 25 \text { days) }\end{array}$ & 87,485 & $\begin{array}{r}\mathbf{1 0 2 , 4 2 0} \\
(6,828 \times 15 \\
\text { sessions })\end{array}$ \\
\hline $\begin{array}{l}\text { Second to } \\
\text { Twelfth } \\
\text { month } \\
\text { (for eleven } \\
\text { months) }\end{array}$ & $\begin{array}{l}852,720 \\
\text { (Rs. } 2,584 \text { x 30days x } 11 \text { months) }\end{array}$ & 852,720 & $\begin{array}{r}\mathbf{1 , 1 2 6 , 6 2 0} \\
(6,828 \times 15 \\
\text { sessionsx } \\
11 \text { months })\end{array}$ \\
\hline $\begin{array}{l}\text { Total cost } \\
\text { for one year } \\
\text { Per patient }\end{array}$ & & 940,205 & $1,229,040$ \\
\hline $\begin{array}{l}\text { Average cost } \\
\text { per month } \\
\text { per patient }\end{array}$ & & $\begin{array}{r}\mathbf{7 8 , 3 5 0} \\
(87,485+852,720 / 12 \\
\text { months })\end{array}$ & $\begin{array}{r}\mathbf{1 0 2 , 4 2 0} \\
(1,29,040 / 12 \\
\text { months })\end{array}$ \\
\hline
\end{tabular}




\section{Note}

Irrespective of the dialysis method most patients receive anti-anemic drugs such as Erythropoietin or Mircera. These drug costs are not included in the above cost calculations.

\section{Discussion}

The purpose of this study was to estimate and compare the provider cost of two major RRT methods used at NINDT.

Study used the stepdown approach to calculate the provider costs of both processes. The final result of the study is summarized below.

\section{Haemodialysis (HD)}

Cost of one four-hour cycle of HD (unit cost) is Rs.6828 For a patient undergoing every other day HD for one month, the cost will be Rs. 102,420 (Rs.6828 x 15)

Cost for one year duration for HD per patient isRs. $1,229,040$ (Rs.102,420 x 12)

\section{Continuous Ambulatory Peritoneal Dialysis (CAPD)}

For this process the patient will have to undergo initial five day training at the cost of Rs. 4577 per day. Then the patient will have to conduct the CAPD process at home using the chemicals provided by the NINDT costing Rs. 2,584 per day.

The cost of five day training is Rs. 22,855 (Rs. 4577 x 5) Cost for home based CAPD for the balance 25 days of the 1 st month is Rs. $64,600(2,584 \times 25)$

Total cost to conduct the process for the 1st month is Rs.87,485 (Rs 22,855 + 64,600)

Cost for the next eleven months for the home based CAPD is.853,720 (Rs.2884 x 30days x 11 months)

Therefore, the total cost for CAPD for one year per patient is Rs. 940,205

Hence the difference of provider cost between the two processes is Rs.288,835 per year in favor of CAPD.

\section{Conclusion}

The study shows a difference of Rs.288,835 in favor of CAPD over HD.
The main reason for this is due to HD being a completely a hospital based, machine dependent procedure and CAPD is mainly a homebased procedure after five day training in the hospital.

The annual cost for HD being Rs. 1,229,040 and CAPD being Rs, 940,205 per patient are costly procedures beyond the capability of the average Sri Lankan individual to pay. The government should continue to finance and support both therapies through the national health system.

Final conclusion of the study is that when provider cost is considered CAPD is more cost effective renal replacement therapy for end stage renal failure patients than the HD.

\section{Recommendation}

Since each HD session per person cost is Rs. 6,828 and CAPD cost per dialysis after initial five day training is Rs. 2584 , it is more economical for Sri Lankan authorities to provide facilities for CAPD in a widespread manner for most of the RRT therapy requirements.

To achieve this, it is necessary to conduct:

Advocacy programmes for policy makers and decision makers of the Health Ministry, nephrology consultants and other appropriate officials.

Awareness and educational programmes are needed to update the knowledge, skills, abilities and benefits to the medical officers, nurses, etc.

Facilities should be upgraded in dialysis centers to carry out CAPD process.

Government should intervene effectively to promote CAPD by reducing or removing completely the import duty charge on CAPD materials

Health education programmes should be conducted to convince kidney patients that CAPD is also an efficient method of dialysis.

Further research should be promoted to determine the real cost benefits of CAPD, including the provider cost as well as the economic cost and benefits for patients and it should compare the relevant costs for both CAPD and HD. 


\section{References}

1. Alwis K. (2013) Chronic kidney disease - when scientists disagree - national academy of sciences - Sri Lanka Available at: http://nas-srilanka.org/ chronic-kidney-disease-when-scientists-disagree/ (Accessed: 28 March 2016).

2. Jha, V. (2009) 'Current status of end-stage renal disease care in south Asia', Ethnicity \&disease., 19.

3. Levey, A., Atkins, R., Coresh, J., Cohen, E., Collins, A., Eckardt, K., Nahas, M., Jaber, B., Jadoul, M., Levin, A., Powe, N., Rossert, J., Wheeler, D., Lameire, N. and Eknoyan, G. (2007) 'Chronic kidney disease as a global public health problem: Approaches and initiatives - a position statement from kidney disease improving global outcomes', Kidney international., 72(3), pp. 247-59. 